\title{
A Conceptual Overview of the Self-Presentational Concerns and Response Tendencies of Focus Group Participants
}

\author{
David B. Wooten \\ Department of Marketing \\ University of Michigan \\ Americus Reed II \\ Department of Marketing \\ University of Florida
}

\begin{abstract}
Focus group respondents are often requested to perform tasks that require them to convey information about themselves. However, despite the potential for respondents to have self-presentational concerns, research on focus group productivity has virtually ignored extant scholarship on impression management. This shortcoming is addressed by presenting a conceptual overview of the effects of self-presentational concerns on focus group participation. A product of this overview is a conceptual model that posits that the amount and nature of information that people convey about themselves to others is a function of their eagerness to make desired impressions and their subjective probabilities of doing so. According to the model, when focus group participants are highly motivated to make desired impressions, they may be reluctant to present unbiased images of themselves. However, they are not likely to deceive unless they are confident in their abilities to ascertain and enact desired images. Those who are motivated to make desired impressions but are doubtful of doing so are likely to protect themselves by concealing self-relevant information or avoiding self-relevant issues. Implications of this model for research and practice are discussed.
\end{abstract}

Focus groups are used frequently by marketing practitioners (Burns \& Bush, 1998; Kinnear \& Root, 1988) and occasionally by marketing scholars (e.g., Green \& Alden, 1988) who want to enrich their understanding of consumer behavior. Cost and convenience undoubtedly contribute to their appeal (Fern, 1982a). However, these factors may also contribute to the dearth of studies examining their productivity because few researchers have the resources to conduct such investigations (McDonald, 1993). Consequently, critical inquiry has not kept pace with growth in their use (Advertising Research Foundation, 1985) and our knowledge of them is limited to "a large body of popular wisdom on the subject" (Corfman, 1995, p. 354). Lunt (1996) expressed similar concerns when he asserted that "Those using the methods over the past 40 years or so have evolved ad hoc rules of thumb [italics added] that have been passed down and then formalized in the how-to books as 'good

Requests for reprints should be sent to David B. Wooten, University of Michigan, Business School, 701 Tappan Street, Ann Arbor, MI 48109-1234. E-mail: dbwooten@umich.edu practice"' (p. 82). Morgan and Spanish (1984) offered perhaps the most severe criticism of our knowledge about focus groups when they asserted that "there is nothing sacred (or even necessarily correct) [italics added] about the current way that focus groups are conducted in market research" (p. 255). These criticisms highlight the need for better theory and additional research on the topic of focus groups.

Much of what has been written about focus groups can be classified as either descriptive accounts of procedures and uses (e.g., Bellenger, Bernhardt, \& Goldstucker, 1987; Wells, 1974) or discussions of strengths (e.g., Greenbaum, 1991; Hess, 1968) and limitations (e.g., Yoell, 1974). In fact, the costs and benefits of focus groups have often been debated in articles either for (e.g., McQuarrie \& McIntyre, 1986, 1987) or against (e.g., Seymour, 1987) the use of focus groups for various applications. Proponents (e.g., Greenbaum, 1991; Kitzinger, 1994; Morgan, 1996) emphasize various advantages of group research. For example, cost and speed are often cited (e.g., Wells, 1974). However, focus groups are more than just quick and dirty substitutes for quantitative techniques (McQuarrie \& McIntyre, 1990). They also offer re- 
spondent interaction and other advantages (Hess, 1968). Opponents (e.g., Yoell, 1974) argue that the potential for the group or particular members to exert undue influence on some participants is a major drawback of focus groups. Even some advocates concede that censorship and conformity (Asbury, 1995; Carey \& Smith, 1994) and other response distortions (McQuarrie \& McIntyre, 1990) do occur in focus groups. Critics (e.g., Yoell, 1974) view these occurrences as problems that result in output that is of limited value. The controversy surrounding the utility of focus groups is probably best reflected in the following rhetorical question by a prominent consumer researcher: "How can anything so bad be good?" (Wells, 1974, pp. 2-145).

Although previous writings have produced useful guidelines for practitioners to follow, these guidelines have rarely been tested (e.g., Corfman, 1995; Falco, Patzer, \& Spence, 1998; Fern, 1982a; Nelson \& Frontczak, 1988) or integrated into a theoretical framework (e.g., Calder, 1977; McQuarrie \& McIntyre, 1988, 1990). We address only the latter shortcoming by presenting a conceptual overview of self-presentation and focus group behavior. Because focus group participants are often asked to perform tasks that require them to reveal information about themselves, their responses may be affected by self-presentational concerns. We outline some antecedents of these concerns and discuss outcomes that may ensue when they are excessive. We also present a conceptual model of self-presentation and focus group participation and discuss its implications for future research and practice. However, we begin with a brief review of extant scholarship on focus groups.

\section{BACKGROUND AND LITERATURE REVIEW}

The label focus group is often applied loosely to any type of group interview (McQuarrie, 1996). However, the prototypical focus group is "a small group of people brought together and guided by a moderator through an unstructured, spontaneous discussion about some topic" (Burns \& Bush, 1998, pp. 216-217). Calder (1977) distinguished among three types of focus groups that differ in terms of the type of knowledge they seek to generate and offered important insights about how the type of knowledge sought should influence research design decisions. However, because his typology does not appear to be reflected in practice (Fern, 1982a; McDonald, 1994), it is ignored in this article. Moreover, some social phenomena (e.g., social comparison processes) are likely to affect virtually any focus group (McQuarrie \& McIntyre, 1990), so this theory should shed light on participant behavior in focus groups, broadly defined.

The technique has been used in marketing (Bellenger et al., 1987), sociology (Krueger, 1994), education (e.g., Basch, 1987; Flores \& Alonso, 1995; Vaughn, Schumm, \& Sinagub, 1996), and other applied social science disciplines (e.g., Byers \& Wilcox, 1991; Hoppe, Wells, Morrison, Gillmore, \&
Wilsdon, 1995). It has become so popular that the term focus groups often appears in the popular press (Krueger, 1995). However, despite the numerous and varied uses of focus groups, researchers (e.g., Fern, 1982a; Nelson \& Frontczak, 1988) have primarily examined their use for idea generation and have focused on quantity and quality of ideas generated as key indicators of productivity. This emphasis has persisted despite the belief that focus groups are rarely good sources of new product ideas (Greenbaum, 1993) and the fact that idea generation constitutes only a subset of focus group uses (Corfman, 1997).

Some monographs (e.g., Krueger, 1994; Stewart \& Shamdasani, 1990) have been written to further our understanding of focus groups. Authors of these monographs have reviewed various studies of small group processes to find conditions that facilitate productive group discussions. This approach, which has enabled them to identify factors that are likely to affect group productivity, has one noteworthy limitation. The nature of the tasks involved in many of the studies (e.g., group decision making) differs from the nature of the focus group task. Focus group participants are often asked to state opinions, discuss behaviors, express values, or reveal other self-relevant information. Hence, discussion quality often depends on their willingness to share this information with others. Although the set of factors affecting self-presentation in groups and the set of factors affecting performance on other group tasks may intersect, they are probably not isomorphic. Even when factors are common to different group tasks, they may have different effects on performance outcomes. For example, Fern (1982a) found large groups to produce more ideas than small ones, but Corfman (1997) found self-disclosure to decrease with the size of the group. ${ }^{1}$

Other studies (e.g., Corfman, 1995, 1997; Fern, 1983; Nelson \& Frontczak, 1988) have examined self-disclosure as a measure of focus group output. These studies often draw on work on self-disclosure and disclosure reciprocity (e.g., Altman, 1973; Derlega, Wilson, \& Chaikin, 1976; Jourard, 1971) to support propositions concerning group effects on individuals' willingness to disclose private information in focus group settings. However, findings from that literature may not generalize to focus group settings because many self-disclosure studies (e.g., Altman, 1973; Derlega et al., 1976) examine disclosure in dyads, whereas focus groups have more than two participants. Moreover, because other studies (e.g., Jourard, 1959, 1971) focus on interactions among acquaintances or intimates (Derlega, Metts, Petronio, \& Margulis, 1993), their findings may not apply to a focus group context where groups consisting of strangers are often used or encouraged (Bellenger et al., 1987; Payne, 1976).

\footnotetext{
${ }^{1}$ Fern's (1982a) findings were based on group-level data, whereas Corfman's (1997) findings were based on the individual level of analysis. However, the two studies draw different conclusions about the relation between group size and focus group productivity.
} 
Like self-disclosure, many other focus group activities have the potential to implicate the self. For instance, idea generation involves demonstrations of creativity and competence. If these traits are valued by participants and are on display during social intercourse, then self-presentational concerns are likely to be salient even during focus group sessions that do not involve direct statements of attitudinal positions. Given the limits of other lines of inquiry and the fact that self-presentational concerns may emerge in various focus group settings, an approach that attempts to understand these concerns is warranted-hence, the purpose of this article, which provides a conceptual overview of the effects of self-presentational concerns on the nature and extent of participation in focus groups. ${ }^{2}$

\section{IS SELF-PRESENTATION ALWAYS DETRIMENTAL TO FOCUS GROUP PRODUCTIVITY?}

The mere mention of self-presentation in the context of focus groups is likely to be viewed as an indictment of focus group research, especially because self-presentational concerns undoubtedly give rise to the socially desirable responding (e.g., Yoell, 1974) and social posturing (e.g., Seymour, 1987) cited by focus group critics. However, recent theorizing about focus groups (e.g., McQuarrie \& McIntyre, 1988) suggests that self-presentational concerns among participants can also be beneficial to research sponsors. In their discussion of group difference, McQuarrie and McIntyre argued that group settings produce selection and volume effects that enhance discussion quality. Selection effects reflect the tendency of common concerns to be more probable and idiosyncratic ones to be less probable during group interviews than during individual interviews. Volume effects result from the tendency of common concerns to be more prominent and idiosyncratic ones to be less prominent during group interviews than during individual interviews. Because common concerns are, presumably, the most important ones, the tendency of focus group participants to suppress idiosyncratic concerns results in greater discussion of the major ones. By conceding that group processes bias outcomes, but suggesting that this bias may have positive consequences, McQuarrie and McIntyre (1988) had "made a virtue out of what is typically seen as the Achilles heel of focus groups" (p. 585).

Their contention that group settings affect what people talk about has received empirical support (e.g., Schlosser, 1997). In fact, the mere anticipation of a group discussion affects what people prepare to discuss (Schlosser \& Shavitt,

\footnotetext{
${ }^{2}$ Although we argue that self-presentational concerns may arise even in focus groups that do not require self-disclosure or direct statements of attitudinal positions (e.g., idea generation), our discussion focuses primarily on behavior in focus group settings that do.
}

1999). Although McQuarrie and McIntyre (1988) discussed how self-presentational concerns affect the issues that people talk about during group discussions, they did not consider how these concerns affect the positions that people take on issues. The possibility that severe distortions (e.g., understatements, exaggeration, or even fabrication) may occur as a result of self-presentational concerns means that the group difference may not always be favorable, as McQuarrie and McIntyre appeared to suggest.

When will self-presentational concerns enhance focus group productivity and when will they impede it? On the surface, it appears that focus groups should be beneficial for discussions of topics that evoke self-presentational concerns. For instance, they may be ideal for products that are conspicuous (e.g., Bearden \& Etzel, 1982) or associated with attitudes serving a value-expressive function (e.g., Katz, 1960; Shavitt, 1990; Smith, Bruner, \& White, 1956; Snyder \& DeBono, 1985) because these types of products are often purchased in service of impression management. However, a recent study by Schlosser (1997) casted doubt on this expectation. She found that people tend to discuss fewer, rather than more, social product attributes when they discuss products in a group setting. Because social attributes arise from a shared perspective, people may be reluctant to discuss them with others whose perspective is either unknown or different. Snyder and Swann (1976) found little or no correspondence between private attitudes and public opinions when their participants expected to face others whose attitudes were either unknown or dissimilar. So, it appears that unless group members are known to have a similar perspective to the respondent or relevant reference groups, focus groups may not capture many of the self-presentational concerns that are salient when people purchase or display products. Thus, the question of when self-presentational concerns in focus groups yield positive versus negative effects on discussion quality is not an easy one and may be an empirical one.

When will self-presentational concerns have substantial and when will they have negligible effects on focus group output? Templeton (1994, p. 210) argued that impression management in focus groups is "no huge factor" despite her recognition that almost everyone does some "face-saving or best foot-putting." We agree that impression management is often present, but not always significant, during focus group discussions. However, it may have a significant impact on focus group output if focus group respondents have excessive self-presentational concerns. To answer the question of when impression management in focus groups will be a major factor, it is important to understand factors that heighten self-presentational concerns. We attempt to further this understanding by discussing major antecedents of self-presentational concerns and potential consequences that may arise when these concerns are excessive. 


\section{ANTECEDENTS AND CONSEQUENCES OF SELF-PRESENTATIONAL CONCERNS}

This section draws heavily from Schlenker and Leary's (1982) conceptual overview of self-presentation and social anxiety. Among other things, their manuscript outlines some major antecedents of two important self-presentational concerns. In addition, it discusses social anxiety as a psychological consequence of these two concerns. By considering some behavioral correlates of social anxiety, as well as some response patterns that occur when self-presentational concerns are less overwhelming, we attempt to shed light on self-presentation and response patterns in focus groups.

According to Schlenker and Leary (1982), people become anxious when they are motivated to make desired impressions but doubtful of doing so. Hence, they view social anxiety as a multiplicative function of impression motivation and impression efficacy (Leary, 1983). Expressed symbolically:

$$
\mathrm{SA}=[\mathrm{M} \times(1-\rho)]
$$

where SA is the level of social anxiety, $M$ is impression motivation, and $\rho$ is the subjective probability of making a desired impression. Factors that increase $M$ should increase anxiety as long as $\rho$ is sufficiently low. Inversely, factors that decrease $\rho$ should increase anxiety as long as $M$ is sufficiently high.

Schlenker and Leary (1982) suggested that $M$ increases with the subjective worth of self-presentational outcomes and the salience of interpersonal evaluation (see Figure 1). First, the greater the potential gains (losses) that are associated with interpersonal encounters, the more people should be concerned about reaping (avoiding) those gains (losses). For instance, interactions that evoke images that are central to a person's identity are likely to increase his or her $\mathrm{M}$ because he or she stands to gain or lose something of value in such interactions. Second, the more people perceive their social encounters to have evaluative implications ceteris paribus, the more they should focus on attaining desired outcomes. This, in part, explains why people become anxious during interviews. On the other hand, when people are less motivated to manage impressions, they should not as easily succumb to social pressures. They perceive fewer benefits to managing impressions and, therefore, should be less concerned about the consequences of their words or deeds. Consequently, they are expected to engage in what Leary (1995) referred to as authentic self-presentation (Figure 2). That is, what they disclose about themselves should be consistent with their private self-images instead of reflecting the expectations of some target audience (Leary, 1995).

Impression efficacy is influenced by degree of certainty regarding self-presentational requirements and perceived differences between self-presentational demands and resources (Schlenker \& Leary, 1982). People believe they have greater control over self-presentational outcomes the more they know about how to behave and the more they believe they have the skills to behave appropriately. To achieve their self-presentational goals, they only need to convey images of themselves that are appropriate for the situation at hand. They may do so through stories, attitude statements, self-descriptions, and other tactics (Leary, 1995). People even appear to avoid some issues in favor of others if they have an idea of the issues that are appropriate for the situation at hand (Schlosser \& Shavitt, 1999). However, if $M$ and $\rho$ are both high, the images that people are likely to present to others may be misleading. They may downplay negative attributes or exaggerate positive ones (Roth, Snyder, \& Pace, 1986). Deceptive self-presentation need not involve fabrication. Rather, deception occurs when individuals alter their self-presentations in a way that is likely to cause researchers to draw misleading inferences (see Table 1 for examples of different tactics). These behaviors may not always occur when people are in situations where both $M$ and $\rho$ are high, but they should be more prevalent. Previous research provides some support for this expectation. For example, Chen, Shechter, and Chaiken (1996) found that rather than disagree with research partners about whom they were forewarned, impression-motivated

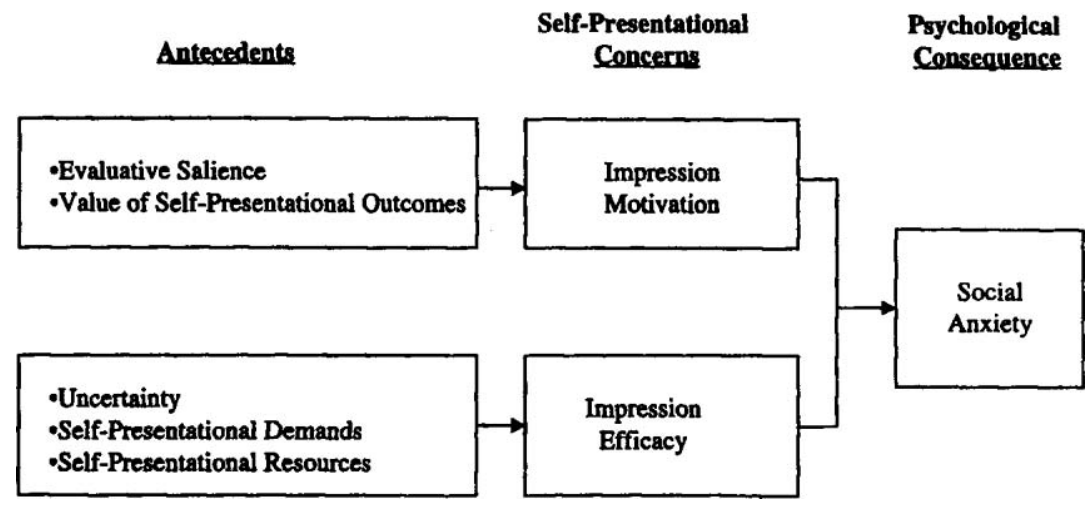

FIGURE 1 Self-presentational basis of social anxiety. Major antecedents suggested by Schlenker and Leary (1982). 


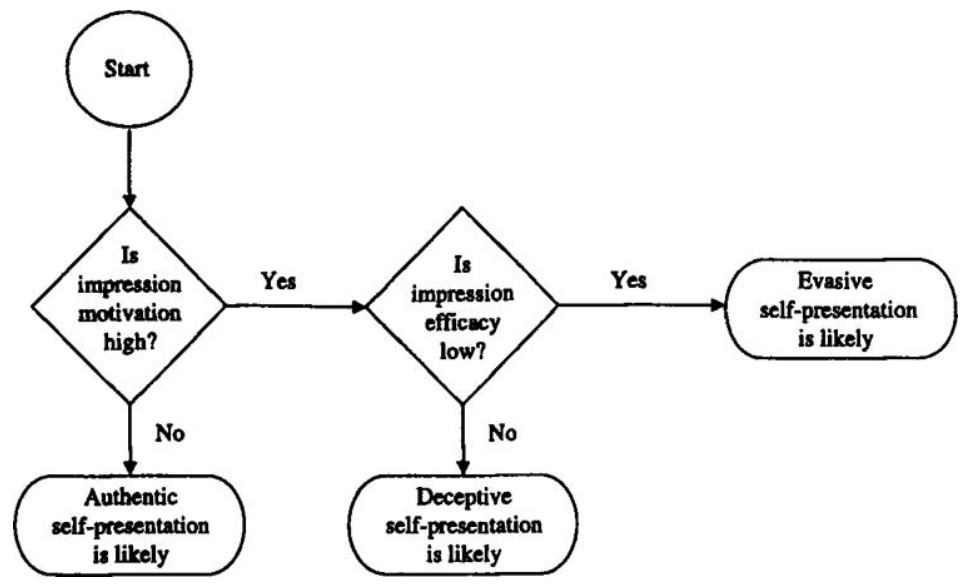

FIGURE 2 Behavioral consequences of self-presentational concerns among focus group participants.

TABLE 1

Inauthentic Self-Presentation Tactics

\begin{tabular}{lll}
\hline Type & \multicolumn{1}{c}{ Tactic } & \multicolumn{1}{c}{ Description } \\
\hline Deceptive & Exaggerating & Increasing to an abnormal degree (e.g., agreement with an opinion or importance of an issue) \\
& Fabricating & Constructing stories or statements that are not literally true \\
& Misattributing & Misallocating credit or blame for outcomes \\
& Selective editing & Systematically withholding comments that are inconsistent with desired impressions \\
& Understating & Stating with less completeness or truth than is warranted (e.g., frequencies) \\
Evasive & Digressing & Giving responses that stray from the main point of the discussion topic \\
& Hedging & Avoiding extreme positions so as not to "go out on a limb" \\
& Repressing & Hushing to avoid taking a position or revealing information about one's self \\
& Stalling & Hushing until one has determined which impressions are desired and how to make them \\
\hline
\end{tabular}

research participants were likely to express views that were consistent with those of their partners. Hence, censorship and conformity (e.g., Carey \& Smith, 1994) may occur.

Thus far, we have discussed settings in which self-presentational concerns are not likely to interfere with social intercourse. That is, people tend to be secure in situations where $\mathrm{M}$ is low or $\rho$ is high (Leary \& Kowalski, 1995). However, social interaction is often problematic for people who are in situations where $M$ is high and $\rho$ is low. In these situations, people want to impress others, but they lack a script to guide their behavior or they lack the skills to enact the script (Leary \& Kowalski, 1995). Hence, they become socially anxious, and they tend to adopt self-presentational styles that are protective rather than acquisitive (Arkin, 1981; Arkin, Lake, \& Baumgardner, 1986). That is, they attempt to avoid looking bad instead of trying to look good. To do so, they may speak less often (Cheek \& Buss, 1981; Meleshko \& Alden, 1993; Pilkonis, 1977), disclose less information about themselves (Snell, 1989), avoid expressing extreme positions (Arkin, 1981; Meleshko \& Alden, 1993), or use other safe verbal response modes (Leary, Knight, \& Johnson, 1987). Fern (1982b) even suggested that focus group participants who feel inhibited tell stories, make irrelevant remarks, or use other digressions to avoid looking foolish. They also may avoid contributing to discussions until they have heard comments from others. This allows them to get familiar with others to reduce the likelihood of making undesired impressions. Leary (1995) referred to the tendency of people to become silent, evasive, or noncommittal when they are socially anxious as evasive self-presentation because they attempt to edit self-relevant information or avoid self-relevant issues.

To summarize this discussion in a focus group context, if conditions exist that cause focus group participants to have high impression motivation, then their participation should be affected. In particular, they should be less likely to present unbiased images of themselves to the group. Instead, they are likely to avoid revealing their true opinions on some, if not all, aspects of the discussion. Moreover, they should be more likely to be evasive or deceptive when presenting information about themselves the more they stand to gain from doing so (Leary, 1995). The likelihood of deceptive self-presentation should be greatest among participants who have high impression motivation and the ability to enact desired impressions. These people believe that they know how to behave and they have the incentive and skills to act accordingly. Hence, their public expressions may differ in strength or direction from their private opinions, or the issues that they emphasize in public may not be the ones that they consider privately. Focus 
group participants should be more inclined to be evasive when they are doubtful of making desired impressions. Evasive self-presentation is most likely to occur among focus group participants who are motivated to make desired impressions but are doubtful of doing so. These people are likely to experience social anxiety (Schlenker \& Leary, 1982) and focus on protective self-presentation (Arkin, 1981). Because they lack the knowledge or ability to look good in the eyes of others, they may clam up to avoid looking bad. For convenience, a model combining the antecedents and behavioral consequences of excessive self-presentational concerns is presented in Figure 3.

\section{IMPLICATION FOR RESEARCH AND PRACTICE}

Stewart and Shamdasani (1990) conducted an extensive review of small group process research and identified many variables that have influenced the productivity of various group tasks. Some practitioners (e.g., Templeton, 1994) have agreed that some of these factors do indeed affect focus group dynamics. In the following section, we discuss some characteristics of the group, its members, the discussion topic, and other factors that may affect focus group participation by causing greater self-presentational concerns among participants. We do not intend to offer a comprehensive review of factors that have previously been identified, nor do we claim to identify new ones. Rather, our goal is to consider a few variables, some of which are based on rules of thumb, and discuss these variables in terms of the proposed model.

\section{Group Characteristics}

Existing guidelines for conducting focus groups suggest that groups should consist of 8 to 12 homogeneous members
(Churchill, 1995; Fern, 1983) who are unacquainted with each other (Payne, 1976). However, there is not unanimity of thought regarding the appropriate size (Fern, 1983), merits of homogeneity (Corfman, 1995), or desired degree of familiarity among members (Nelson \& Frontczak, 1988). The appropriate number and mix of participants may depend on the research goals or the type of focus group conducted (Calder, 1977). Scholars have suggested conditions under which the appropriate group size may vary within the recommended range (e.g., Wells, 1974), fall below it (e.g., Krueger, 1995), or exceed it (e.g., Merton, Fiske, \& Kendall, 1990) without undue deterioration in discussion quality. The norm in Europe is 6 to 8 respondents per group (Cooper, 1989). Although we cannot specify the optimal group size, we can shed light on some effects of group size on self-presentation.

The theory of social impact (e.g., Jackson \& Latane, 1981; Latane, 1981; Latane \& Harkins, 1976; Latane \& Wolf, 1981) suggests that performance pressures increase and social actors become more anxious as the size of their audience increases. Leary and Kowalski (1995) suggested two reasons why this is so. First, impression motivation may increase because social and psychological stakes are greater the more people there are to witness a performance. "Put another way, it is better to make a good impression, but worse to make a bad impression, on 50 as opposed to 5 other people" (Leary and Kowalski, 1995, p. 41). Because the value of self-presentational outcomes increases with the size of the audience, impression motivation should increase and self-presentation should be affected. Second, impression efficacy may decrease with the size of a group. People are likely to be less certain about self-presentational outcomes when they face large as opposed to small audiences because their demands tend to increase with the number of people present (Leary \& Kowalski, 1995). The social skills that are involved in interactions with a larger group often differ from those involved in common contingent conversations. If impression motivation increases and impression efficacy decreases as the size of a focus group increases, then evasive self-presentation should be more likely as group size increases.

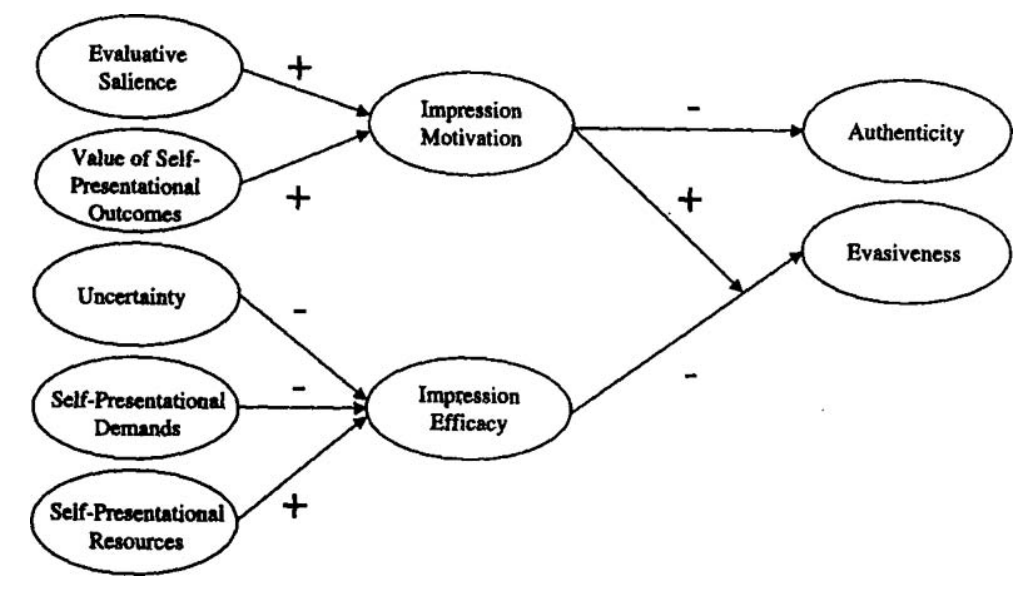

FIGURE 3 Self-presentational and response patterns in focus groups. 
Another rule of thumb about focus groups is that within-group homogeneity should be maintained (Fern, 1983). For instance, some have argued for similar educational backgrounds (Merton et al., 1990), social status (Merton et al., 1990; Wells, 1974), and interests (Levy, 1979) among participants. Similarity in terms of gender (Wells, 1974), age (Greenbaum, 1998), and stage of the family life-cycle (Wells, 1974) have also been advocated. Calder (1977) emphasized the importance of member homogeneity for phenomenological focus groups where an everyday understanding of a shared perspective is desired. Because each person is likely to have many perspectives (Charon, 1998), it is important that the one that is shared is made salient during the discussion. Moreover, because homogeneity is a multifaceted concept (Corfman, 1995), the question of how similar people should be may be less important than the question of on which dimensions should they be similar. For example, studies that have shown interpersonal attraction to increase with perceived attitude similarity (e.g., Byrne, 1961; Sheffield \& Byrne, 1967) and similarity on sociodemographic variables (Kandel, 1978; Sykes, Larntz, \& Fox, 1976) suggest that impression motivation may be high when people are among others with similar attitudes and external characteristics. If interpersonal attraction is higher, then the payoffs (e.g., acceptance) associated with managing impressions may also be higher. So impression motivation should be high during interactions among people who are similar on these dimensions. On the other hand, if status or expertise is the basis of similarity, then impression motivation may be highest when people are forced to interact with dissimilar others. People tend to be more tense when they interact with people of higher status than when they are among people of lower status (Latane, 1981; Latane \& Harkins, 1976) because people of higher status are more likely to be in positions to mediate valued rewards (Schlenker \& Leary, 1982). So, the effects of homogeneity on impression motivation can be either positive or negative, depending on the basis of homogeneity. People can differ on many dimensions, so it is important to know which ones to make salient during social interaction. Hence, additional efforts along the lines of Corfman (1995) are needed to define relevant dimensions of homogeneity and relate them to designated measures of focus group output.

The effects of homogeneity on impression efficacy appear to be easier to ascertain than are its effects on impression motivation. If the basis of similarity is issue related, then impression efficacy should increase with homogeneity. That is, individuals should be more certain about what constitutes appropriate responses when there is minimal variance in the responses of others. "In the presence of clear and unambiguous social or interpersonal cues to situational appropriateness, correspondence between social behavior and these situational factors should be substantial" (Snyder \& Swann, 1976, p. 1040). If perceived status is the basis of similarity, then the effect of homogeneity on impression efficacy should be in a similar direction, but for a different reason. People of high status may be perceived as more demanding than their lower status counterparts, so they may be more difficult to impress. The greater demands imposed on individuals of low status by their high status counterparts means that impression efficacy should be low, but primarily for low status individuals in the group. Because impression efficacy is expected to be low for some members of heterogeneous (in terms of status) groups, those who are motivated to make desired impressions may be evasive. This may explain why Krueger (1998) expected some people to be inhibited and to defer to others when groups are heterogeneous in terms of expertise or status. In summary, it appears that, on many dimensions, greater heterogeneity leads to lower impression efficacy among some, if not all, focus group members. Therefore, participants are likely to be evasive in these situations.

Focus groups probably should not have a skewed distribution of social types within a group. That is, a group probably should not contain an individual who differs from the other members on a salient dimension. This sentiment is reflected in the comments of Bellenger et al. (1987) about the value of integrated focus groups: "Even those [who] argue for integration, however, say that one token Black may be worse than no Blacks at all; it is usually better to have two to three Blacks out of ten" (p. 10). Distinctiveness effects are not limited to race or ethnicity; they also hold for gender (Kanter, 1977; Wooten, 1995). Distinctive individuals tend to alter their behaviors in predictable ways when they are members of otherwise homogeneous groups because as salient characteristics become more distinctive, the individuals who posses them become more publicly self-conscious and more concerned about matching their behaviors to salient standards (Mullen, 1983,1986 ). Because publicly self-conscious people tend to view themselves through the eyes of others, increased public self-consciousness has the effect of increasing the salience of interpersonal evaluation. Therefore, we expect that distinctive people will have high impression motivation because of the perceived salience of interpersonal evaluation. Hence, they should be less likely to present authentic images of themselves in this setting than they would in settings where they are not as distinctive. However, their use of evasive versus deceptive self-presentation tactics should depend on the nature of the images that they wish to convey and the ease with which they believe they can convey them.

Familiarity or acquaintanceship among focus group participants has also been thought to have an adverse effect on focus group dynamics (Bellenger et al., 1987; Payne, 1976). Wells (1974) acknowledged that there are costs and benefits of conducting focus groups consisting of acquainted members. On the one hand, people may be less candid in the presence of people they expect to see again. On the other hand, conversation should flow more easily and be more natural when group members see each other on a regular basis. Self-presentation theorists (e.g., Jones \& Goethals, 1972) argue that people often have the most at stake during initial encounters. This would suggest that impression motivation is likely to be higher when a social actor is among strangers than 
when he or she is among acquaintances. Indeed, Leary et al. (1994) found this to be true. Their participants felt a greater need to make desired impressions to a stranger than to a familiar target. However, this effect is most likely to occur when the person expects future interactions with the target (Baumeister, 1982; Gergen \& Wishnov, 1965) because the value of self-presentational outcomes tends to be greater when future interactions are expected (Leary, 1995). So, groups consisting of members who are all acquainted and groups consisting of total strangers who do not expect to interact in the future may both be characterized by low impression motivation. However, impression motivation appears to be highest when focus groups consist of strangers with whom future interactions are expected.

The relation between familiarity and impression efficacy is also complicated. Because social actors should know how to behave in front of familiar audiences (Schlenker \& Leary, 1982), uncertainty should be low and impression efficacy high for those who are in the company of familiar others. In this case, one may expect a free-flowing conversation because participants should have little or no reason to be inhibited about what to say. However, this freedom is constrained by the fact that social actors tend to have a limited number of roles that they can play when their audience is highly familiar with them (Baumeister \& Jones, 1978). This may explain why people exhibit greater modesty (Tice, Butler, Muraven, \& Stillwell, 1995) and do less name-dropping (Bohra \& Pandey, 1984) when they are around friends than when among strangers. Because people are likely to know how to avoid social blunders when they are among acquaintances, they may not feel the need to be evasive with them. Moreover, because people appear to be constrained by their reputations during interactions with acquaintances, they may have less freedom to deceive them. So, self-presentation theory appears to contradict popular wisdom about conducting focus groups among acquaintances. This discussion assumes that all focus group members are acquainted with each other. However, arguments against acquainted participants (e.g., Bellenger et al., 1987) tend to emphasize the disruptive effects of private conversations that occur when only a few members are acquainted. Future research should examine how focus group productivity may vary with the proportion of acquainted versus unacquainted members.

The historical preference for having groups that consist of strangers instead of acquaintances appears to reflect a desire to approximate conditions of anonymity while maintaining some semblance of a normal social encounter. In fact, efforts to conduct focus groups in environments (e.g., Internet focus groups) that more closely approximate conditions of anonymity have been criticized for lacking the social dynamics of traditional focus groups (Greenbaum, 1997). Although attempts to ensure anonymity may cause focus group researchers to forfeit some respondent interaction advantages, they appear to offer the advantage of reducing impression motivation by lowering the perceived social costs and benefits of participation. Hence, conditions of anonymity are likely to produce discussions that are relatively free of response distortions. This relation has been found in previous research. For example, Saegert, Fractor, and Mandell (1980) found that focus group participants who responded privately to a sensitive topic (i.e., grades) were more honest than were those who responded publicly. However, not all respondents who were assured anonymity were truthful. Kiely (1998) found Internet focus groups, which protect respondents identities, to be more productive than are traditional ones. He attributed the productivity gains in Internet focus groups to greater levels of participation from socially reticent respondents. So, it appears that anonymity may be beneficial for certain types of discussions (e.g., sensitive ones) or certain types of people (e.g., socially anxious ones). Future research is needed to identify conditions that moderate the effects of anonymity on group research productivity. Future research should also consider other group productivity measures to advance our understanding of the costs and benefits of anonymity in focus groups.

\section{Individual Characteristics}

According to Templeton (1994), "Almost everyone does a certain amount of face-saving and best foot-putting" (p. 10). However, extant scholarship in personality and social psychology suggests that people may differ in the extent to which they monitor their social environments (Snyder, 1987) and seek social validation (Crowne \& Marlowe, 1964). For example, people who score high on the public self-consciousness scale (Fenigstein, Scheier, \& Buss, 1975) are often concerned about self-presentation and interpersonal evaluation (Carver \& Scheier, 1981; Doherty \& Schlenker, 1991). People who are high self-monitors (Snyder, 1974) or pay attention to social comparison information (Lennox \& Wolfe, 1984) appear to have similar concerns. These types of people are likely to be highly responsive to group norms. Their concerns for how others perceive them are likely to motivate them to manage impressions and make them behave strategically when revealing information to others. Discussion quality could either be enhanced by selection and volume effects or be damaged by severe distortions. The extent to which the outcome is positive or negative may depend on the composition of the group, perceptions of impression efficacy, and the types of self-presentation tactics used.

Individual differences also exist in how people view their prospects of making desired impressions. For example, people with low self-esteem tend to view situations more pessimistically than do their high self-esteem counterparts. Consequently, they tend to exhibit less self-aggrandizing (Schlenker, Weigold, \& Hallam, 1990), more self-protective behaviors (Wolfe, Lennox, \& Cutler, 1986), more indirect forms of self-enhancement (Brown, Collins, \& Schmidt, 1988), or other safe ways to gain stature (Wood et al., 1994). These behavior patterns become even more pronounced in 
public settings (Baumeister, Tice, \& Hutton, 1989). People with low self-esteem perceive their self-presentational resources to be insufficient to meet their interpersonal demands. Consequently, in situations where they are highly motivated to make desired impressions, they are likely to be cautious or evasive. The end result may be less data and fewer insights from these types of people.

\section{Discussion Topic}

Self-presentation in focus groups may also be influenced by the discussion topic. For example, people may be reluctant to admit to indulging in guilty pleasures like consuming pornography or reading tabloids. They may also avoid divulging other information that is of a sensitive nature (Stewart \& Shamdasani, 1998). Focus group advocates (e.g., Greenbaum, 1991) have argued that the list of topics that people will not discuss in focus groups is quite small. As evidence, they (e.g., Carey \& Smith, 1994) cited studies that have used focus groups to understand risk factors in HIV transmission and breast self-examinations among women. Although focus group participants may actually talk about these issues, the extent to which their words will reflect their actual feelings or actions is unclear. People tend to be deceptive or evasive when they are asked to reveal information that may threaten their identities. For example, medical patients have been found to fabricate responses to questions from medical personnel (Leary \& Kowalski, 1995) and to underreport symptoms (Carver, Coleman, \& Glass, 1976) to avoid embarrassment. If people conceal and distort information about themselves, which may be detrimental to their health, then they are likely to behave similarly in focus groups where the consequences of doing so are less harmful. When people discuss sensitive topics with others, they are likely to be cognizant of the risks they face by doing so. The high social (e.g., stigmatization) and psychological stakes (e.g., embarrassment) involved may increase their impression motivation. Hence, they may be apprehensive about divulging their secrets, selective in what they reveal, or even deceptive in their self-presentations.

Focus group participants are likely to have high impression motivation not only during discussions that have the potential to threaten their identities, but also during discussions that evoke images that are important to them. "People will be more motivated to create a preferred impression on others when the interaction focuses on images that are more rather than less central to their identities" (Schlenker \& Leary, 1982, p. 648). For example, if someone is so involved with a topic (e.g., motorcycles) that it becomes a basis for self-definition (e.g., Harley rider), then he or she may behave strategically when discussing the topic. Response distortions (e.g., exaggeration) are likely because the person stands to gain some- thing of value to him or her (i.e., deference) by making desired impressions.

\section{Other Factors}

Other factors, such as the moderator (e.g., McDonald, 1993, 1994; Stewart \& Shamdasani, 1998) or the physical environment (e.g., Stewart \& Shamdasani, 1990), may also affect self-presentation and respondent behavior in focus groups. Because the moderator can have a major impact on the quality of focus group output (Fern, 1983), efforts to identify good moderator traits (e.g., Axelrod, 1976; Langer, 1978) and effective moderating tactics (e.g., Greenbaum, 1993; Wells, 1974) have been undertaken. For example, Kennedy (1976) warned that verbal and nonverbal cues from moderators affect participants' responses because these cues can be interpreted as signs of approval or disapproval. If so, then these cues may increase the salience of interpersonal evaluations, thereby increasing the extent to which some participants are motivated to make desired impressions. Moreover, these cues may provide information about desired responses. So, not only may these cues make respondents more eager to make desired impressions, but they also may make respondents better able to do so. Therefore, respondents may be more inclined to resort to deception when moderators give off certain cues.

Characteristics of the physical environment may also affect participation in focus groups (Krueger, 1994; Stewart \& Shamdasani, 1990). Even the seating arrangements can potentially make a difference (Corfman, 1997). People form impressions of others based on their surroundings (Burroughs, Drews, \& Hallman, 1991). These impressions may influence their behaviors toward others. So, for example, if a focus group facility causes participants to perceive the researcher or sponsoring organization as a high status other, then participants may be intimidated and, consequently, evasive. People also manage impressions by manipulating characteristics of their physical surroundings (Ornstein, 1989). For example, people sometimes choose their seating locations so as to make desired impressions (Reiss, 1982). If characteristics of the physical environment are useful for impression construction, then physical surroundings may affect impression efficacy. For example, the seating arrangements or one's inability to get a desired seat during a focus group discussion may affect his or her subjective probability of making desired impressions. The effects of physical layout (e.g., seating arrangements) on focus group participation deserve thoughtful consideration in future research.

\section{DISCUSSION}

This article provides a conceptual overview of self-presentation and focus group behavior to shed light on the question of how focus groups work. Such an overview is war- 
ranted by the fact that focus group participants are often asked to perform tasks that require them to reveal something about themselves. A product of our overview is a parsimonious model that considers the nature of interpersonal interaction and has implications for research and practice. On the research front, we discussed several factors that appear to have predictable effects on individuals' self-presentational concerns and strategies. Therefore, we have attempted to lay the groundwork for future empirical work. On the practice front, we attempted to shed light on interpersonal interaction in focus group settings so that users of focus groups can gain a better understanding of how and why they work. This understanding cannot be fully achieved if existing rules of thumb about focus groups go unquestioned or untested.

The proposed model is based on a conceptual overview of the self-presentational basis for social anxiety (Schlenker \& Leary, 1982). That article outlines the major antecedents and discusses an important psychological consequence of excessive self-presentational concerns. We attempted to extend that conceptual model by integrating findings on the behavioral consequences of social anxiety and self-presentational concerns. Therefore, our model represents both an application and an extension of their work. Although this article has the potential to contribute to the impression management literature, it was written in response to criticisms about the state of our knowledge about focus groups.

\section{Limitations}

This article focuses exclusively on the effects of self-presentational concerns on focus group participation. Consequently, it ignores some of the more pragmatic issues that may affect focus group participation. For example, people should be expected to speak less frequently as the size of the group increases because they are likely to have greater competition for "air time" and fewer opportunities to speak. Furthermore, screening for personality types that are prone to have self-presentational concerns will increase the cost of recruitment. Obviously, these issues should be taken into account.

This article considers how self-presentational concerns affect individual response tendencies, but it does not address how these tendencies affect overall group performance. However, some individual behaviors may reverberate throughout groups. For example, Camacho and Paulus (1995) found that socially anxious people are not only less productive than other group members, but they also make others less productive, presumably by affecting performance standards. Although this finding was based on an idea generation task, a similar effect may be obtained in a group discussion, if disclosure reciprocity (e.g., Altman, 1973) is expected with groups of more than two people. The tendency for people to distort their private opinions in a public setting may also be contagious. If a few impression-motivated group members distort or moderate their views (e.g., Chen et al., 1996), then other members may perceive greater uniformity within the group and, therefore, feel greater pressure to conform. This domino effect may enhance productivity by magnifying selection and volume effects (McQuarrie \& McIntyre, 1988, 1990), but it may also produce misleading results. Future research is needed to examine the extent to which these individual effects are contagious. In addition, research is needed to determine when these effects are beneficial and when they are detrimental to focus group productivity.

\section{Conclusions}

In conclusion, this article echoes the themes from previous calls that encourage researchers to challenge (e.g., Morgan \& Spanish, 1984) and test (e.g., Corfman, 1995) existing rules of thumb for conducting focus groups. For example, Krueger (1995) classified some specific rules of thumb regarding group size and composition as myths that, based on his experience, are not to be believed. Although this article is based more on self-presentation theory than on practical experience, it concludes with a similar recommendation. Researchers should challenge and test some of the current "tricks of the trade." Moreover, attempts to identify or develop measures of focus group output, other than quantity and quality of ideas, are encouraged. For example, Corfman $(1995,1997)$ attempted to measure self-disclosure. Similar efforts are needed to identify measures of evasiveness such as the Self-Concealment Scale (Larson \& Chastain, 1990) or measures of intentional deception (e.g., Paulhus, 1988) before this theory can be tested.

\section{ACKNOWLEDGMENTS}

Americus Reed II is now an Assistant Professor at the Wharton School, University of Pennsylvania. We thank Kim Corfman, Barry Schlenker, and Michael Weigold for their input during initial stages of this research. We also thank the editor and two anonymous reviewers for their helpful comments on an earlier draft of this article.

\section{REFERENCES}

Advertising Research Foundation. (1985). Focus groups: Issues and approaches. New York: Author.

Altman, I. (1973). Reciprocity of interpersonal exchange. Journal for the Theory of Social Behaviour, 3, 249-261.

Arkin, R. (1981). Self-presentation styles. In J. Tedeschi (Ed.), Impression management theory and social psychological research (pp. 311-333). New York: Academic.

Arkin, R., Lake, E., \& Baumgardner, A. (1986). Shyness and self-presentation. In W. Jones, J. Cheek, \& S. Briggs (Eds.), Shyness: Perspectives on research and treatment (pp. 189-203). New York: Plenum. 
Asbury, J. (1995). Overview of focus group research. Qualitative Health Research, 5, 414-420.

Axelrod, M. (1976). The dynamics of the group interview. In B. Anderson (Ed.), Advances in consumer research (Vol. 3, pp. 437-441). Ann Arbor, MI: Association for Consumer Research.

Basch, C. (1987). Focus group interview: An underutilized research technique for improving theory and practice in health education. Health $E d$ ucation Quarterly, 14, 411-448.

Baumeister, R. (1982). Self-esteem, self-presentation, and future interaction: A dilemma of reputation. Journal of Personality, 50, 29-45.

Baumeister, R., \& Jones, E. (1978). When self-presentation is constrained by the target's knowledge: Consistency and compensation. Journal of Personality and Social Psychology, 36, 608-618.

Baumeister, R., Tice, D., \& Hutton, D. (1989). Self-presentational motivations and personality differences in self-esteem. Journal of Personality, $57,547-579$.

Bearden, W., \& Etzel, M. (1982). Reference group influence on product and brand purchase decisions. Journal of Consumer Research, 9, 183-194.

Bellenger, D., Bernhardt, K., \& Goldstucker, J. (1987), Qualitative research in marketing. Chicago: American Marketing Association.

Bohra, K., \& Pandey, J. (1984). Ingratiation toward strangers, friends, and bosses. The Journal of Social Psychology, 122, 217-222.

Brown, J., Collins, R., \& Schmidt, G. (1988). Self-esteem and direct versus indirect forms of self-enhancement. Journal of Personality and Social Psychology, 55, 445-453.

Burns, A., \& Bush, R. (1998). Marketing research (2nd ed.). Upper Saddle River, NJ: Prentice Hall.

Burroughs, W., Drews, D., \& Hallman, W. (1991). Predicting personality from personal possessions: A self-presentational analysis. Journal of Social Behavior and Personality, 6, 147-163.

Byers, P., \& Wilcox, J. (1991). Focus groups: A qualitative opportunity for researchers. The Journal of Business Communication, 28, 63-78.

Byme, D. (1961). Interpersonal attraction and attitude similarity. Journal of Abnormal and Social Psychology, 62, 713-715.

Calder, B. (1977). Focus groups and the nature of qualitative marketing research. Journal of Marketing Research, 14, 353-364

Camacho, L., \& Paulus, P. (1995). The role of social anxiousness in group brainstorming. Journal of Personality and Social Psychology, 68, 1071-1080.

Carey, M., \& Smith, M. (1994). Capturing the group effect in focus groups: A special concern in analysis. Qualitative Health Research, 4, 123-127.

Carver, C., Coleman, A., \& Glass, D. (1976). The coronary-prone behavior pattern and the suppression of fatigue on a treadmill test. Journal of Personality and Social Psychology, 33, 460-466.

Carver, C., \& Scheier, M. (1981). Attention and self-regulation: A control-theory approach to human behavior. New York: Springer-Verlag.

Charon, J. (1998). Symbolic interactionism: An introduction, an interpretation, an integration (6th ed.). Upper Saddle River, NJ: Prentice Hall.

Cheek, J., \& Buss, A. (1981). Shyness and sociability. Journal of Personality and Social Psychology, 41, 330-339.

Chen, S., Shechter, D., \& Chaiken, S. (1996). Getting at the truth or getting along: Accuracy-versus impression-motivated heuristic and systematic processing. Journal of Personality and Social Psychology, 71 . $262-275$.

Churchill, G. (1995). Marketing research: Methodological foundations (6th ed.). Fort Worth, TX: Dryden.

Cooper, P. (1989). Comparison between the UK and US: The qualitative dimension. Journal of the Market Research Society, 31, 509-520.

Corfman, K. (1995). The importance of member homogeneity to focus group quality. In F. Kardes \& M. Sujan (Eds.), Advances in consumer research (Vol. 22, pp. 354-359). Provo, UT: Association for Consumer Research.

Corfman, K. (1997). Determinants of participation in focus group discussions. Unpublished manuscript.

Crowne, D., \& Marlowe, D. (1964). The approval motive: Studies in evaluative dependence. New York: Wiley.
Derlega, V., Metts, S., Petronio, S., \& Margulis, S. (1993). Self-disclosure. Newbury Park, CA: Sage.

Derlega, V., Wilson, M., \& Chaikin, A. (1976). Friendship and disclosure reciprocity. Journal of Personality and Social Psychology, 34, 578-582.

Doherty, K., \& Schlenker, B. (1991). Self-consciousness and strategic self-presentation. Journal of Personality, 59, 1-18.

Falco, J., Patzer, A., \& Spence, M. (1998). How group size affects the quality of an individual's contribution to a focus group: An empirical study. Business Journal, 13(1-2), 36-40.

Fenigstein, A., Scheier, M., \& Buss, A. (1975). Public and private self-consciousness: Assessment and theory. Journal of Consulting and Clinical Psychology, 43, 522-527.

Fern, E. (1982a). The use of focus groups for idea generation: The effects of group size, acquaintanceship, and moderator on response quantity and quality. Journal of Marketing Research, 19, 1-13.

Fern, E. (1982b). Why do focus groups work: A review and integration of small group process theories. In A. Mitchell (Ed.), Advances in consumer research (Vol. 9, pp. 444 451). Ann Arbor, MI: Association for Consumer Research.

Fern, E. (1983). Focus groups: A review of some contradictory evidence, im plications, and suggested future research. In R. Bagozzi \& A. Tybout (Eds.), Advances in consumer research (Vol. 10, pp. 121-126). Ann Arbor, MI: Association for Consumer Research.

Flores, J., \& Alonso, C. (1995). Using focus groups in educational research. Evaluation Review, 19, 84-101.

Gergen, K., \& Wishnov, B. (1965). Others' self-evaluations and interaction anticipation as determinants of self-presentation. Journal of Personality and Social Psychology, 2, 348-358.

Green, R., \& Alden, D. (1988). Functional equivalence in cross-cultural consumer behavior: Gift giving in Japan and the United States. Psychology \& Marketing, 5, 155-168.

Greenbaum, T. (1991, September 2). Focus groups vs. one-on-ones: The controversy continues. Marketing News, 25, 16.

Greenbaum, T. (1993). The handbook for focus group research, revised and expanded edition. Lexington, MA: Lexington.

Greenbaum, T. (1997, March 3). Internet focus groups: An oxymoron. Marketing News, 31, 35-36.

Greenbaum, T. (1998). The handbook for focus group research (2nd ed.) Thousand Oaks, CA: Sage.

Hess, J. (1968). Group interviewing. In R. King (Ed.), New science of planning (pp. 193-196). Chicago: American Marketing Association.

Hoppe, M., Wells, E., Morrison, D., Gillmore, M., \& Wilsdon, A. (1995) Using focus groups to discuss sensitive topics with children. Evaluation Review, 19, 102-114.

Jackson, J., \& Latane, B. (1981). All alone in front of all those people: Stage fright as a function of number and type of co-performers and audience. Journal of Personality and Social Psychology, 40, 73-85.

Jones, E., \& Goethals, G. (1972). Order effects in impression formation: At tribution context and the nature of the entity. In E. Jones, D. Kanouse, $H$ Kelley, R. Nisbett, S. Valins, \& B. Weiner (Eds.), Attributions: Perceiving the causes of behavior (pp. 27-46). Hillsdale, NJ: Lawrence Erlbaum Associates, Inc

Jourard, S. M. (1959). Self-disclosure and other-cathexis. Journal of Abnormal and Social Psychology, 59, 428-431.

Jourard, S. M. (1971). The transparent self (2nd ed.). Princeton, NJ: Van Nostrand Reinhold.

Kandel, D. (1978). Similarity in real-life adolescent friendship pairs. Journal of Personality and Social Psychology, 36, 306-312.

Kanter, R. (1977). Some effects of proportions on group life: Skewed sex ratios and responses to token women. American Journal of Sociology, 82, 965-990.

Katz, D. (1960). The functional approach to the study of attitudes. Public Opinion Quarterly, 24, 163-204.

Kennedy, F. (1976). The focused group interview and moderator bias. Marketing Review, 31, 19-21. 
Kiely, T. (1998). Wired focus groups. Harvard Business Review, 76(1), 12, $14,16$.

Kinnear, T. C., \& Root, A. R. (1988). Survey of marketing research. Chicago: American Marketing Association.

Kitzinger, J. (1994). The methodology of focus groups: The importance of interaction between research participants. Sociology of Health \& $\mathrm{lll}$ ness, 16, 103-121.

Krueger, R. (1994). Focus groups (2nd ed.). Thousands Oaks, CA: Sage.

Krueger, R. (1995). The future of focus groups. Qualitative Health Research, 5. 524-530.

Krueger, R. (1998). Moderating focus groups. Thousands Oaks, CA: Sage.

Langer, J. (1978, September 8). Clients: Check qualitative researcher's personal traits to get more; Qualitative researchers: Enter entire marketing process to give more. Marketing News, 12, 10-11.

Larson, D., \& Chastain, R. (1990). Self-concealment: Conceptualization, measurement, and health implications. Journal of Social and Clinical Psychology, 9, 439-455.

Latane, B. (1981). The psychology of social impact. American Psychologist, 36, 343-356.

Latane, B., \& Harkins, S. (1976). Cross-modality matches suggest anticipated stage fright a multiplicative power function of audience size and status. Perception and Psychophysics, 20, 482-488.

Latane, B., \& Wolf, S. (1981). The social impact of majorities and minorities. Psychological Review, 88, 438-453.

Leary, M. (1983). The conceptual distinctions are important: Another look at communication apprehension and related constructs. Human Communication Research, 10, 305-312.

Leary, M. (1995). Self-presentation: Impression management and interpersonal behavior. Madison, WI: WCB Brown \& Benchmark Publishers.

Leary, M., Knight, P., \& Johnson, K. (1987). Social anxiety and dyadic conversation: A verbal response analysis. Journal of Social and Clinical Psychology, 5, 34-50.

Leary, M., \& Kowalski, R. (1995). Social anxiety. New York: Guilford.

Leary, M., Nezlek, J., Downs, D., Radford-Davenport, J., Martin, J., \& McMullen, A. (1994). Self-presentation in everyday interactions: Effects of target familiarity and gender composition. Journal of Personality and Social Psychology, 67, 664-673.

Lennox, R., \& Wolfe, R. (1984). Revision of the self-monitoring scale. Journal of Personality and Social Psychology, 46, 1349-1364.

Levy, S. (1979). Focus group interviewing. In J. Higginbotham \& K. Cox (Eds.), Focus group interviews: A reader (pp. 29-37). Chicago: American Marketing Association.

Lunt, P. (1996). Rethinking the focus group in media and communications research. Journal of Communication, 46(2), 79-98

McDonald, W. (1993). Focus group research dynamics and reporting: An examination of research objectives and moderator influences. Journal of the Academy of Marketing Science, 21, 161-168.

McDonald, W. (1994). Provider perceptions of focus group research use: A multicountry perspective. Journal of the Academy of Marketing Science, 22, 265-273.

McQuarrie, E. (1996). The market research toolbox: A concise guide for beginners. Thousand Oaks, CA: Sage.

McQuarrie, E., \& McIntyre, S. (1986). Focus groups and the development of new products by technologically driven companies: Some guidelines. Journal of Product Innovation Management, 3, 40-47.

McQuarrie, E., \& McIntyre, S. (1987). What focus groups can and cannot do: A reply to Seymour. Journal of Product Innovation Management, 4, 55-60.

McQuarrie, E., \& McIntyre, S. (1988). Conceptual underpinnings for the use of group interviews in consumer research. In M. Houston (Ed.), Advances in consumer research (Vol. 15, pp. 580-586). Provo, UT: Association for Consumer Research.

McQuarrie, E., \& McIntyre, S. (1990). What the group interview can contribute to research on consumer phenomenology. In E. Hirschman (Ed.), Research in consumer behavior (Vol. 4, pp. 165-194). Greenwich, CT: JAI.
Meleshko, K., \& Alden, L. (1993). Anxiety and self-disclosure: Toward a motivational model. Journal of Personality and Social Psychology, 64, 1000-1009.

Merton, R., Fiske, M., \& Kendall, P. (1990). The focused interview: A manual of problems and procedures (2nd ed.). New York: Free Press.

Morgan, D. (1996). Focus groups. In J. Hagan \& K. Cook (Eds.), Annual review of sociology (Vol. 22, pp. 129-152). Palo Alto, CA: Annual Reviews, Inc.

Morgan, D., \& Spanish, M. (1984). Focus groups: A tool for qualitative research. Qualitative Sociology, 7, 253-270.

Mullen, B. (1983). Operationalizing the effect of the group on the individual: A self-attention perspective. Journal of Experimental Social Psychology, 19, 295-322.

Mullen, B. (1986). Stuttering, audience size, and the other-total ratio: A self-attention perspective. Journal of Applied Social Psychology, I6, 139-149.

Nelson, J., \& Frontczak, N. (1988). How acquaintanceship and analyst can influence focus group results. Journal of Advertising, 17, 41-48.

Omstein, S. (1989). Impression management through office design. In R. Giacalone \& P. Rosenfeld (Eds.), Impression management in the organization (pp. 411-426). Hillsdale, NJ: Lawrence Erlbaum Associates, Inc.

Paulhus, D. (1988). Assessing self deception and impression management in self-reports: The balanced inventory of desirable responding. Unpublished manuscript, University of British Columbia, Vancouver, Canada.

Payne, M. (1976). Preparing for group interviews. In B. Anderson (Ed.), Advances in consumer research (Vol.3, pp. 434-436). Ann Arbor, MI: Association for Consumer Research.

Pilkonis, P. (1977). The behavioral consequences of shyness. Journal of Personality, 45, 596-611.

Reiss, M. (1982). Seating preferences as impression management: A literature review and theoretical integration. Communication, 11, 85-113.

Roth, D., Snyder, C., \& Pace, L. (1986). Dimensions of favorable self-presentation. Journal of Personality and Social Psychology, 5I, 867-874.

Saegert, J., Fractor, Z., \& Mandell, L. (1980). Validation of a device for obtaining anonymous responses in group interviews. In J. Olson (Ed.), $A d$ vances in consumer research (Vol. 7, pp. 717-719). Ann Arbor, Ml: Association for Consumer Research.

Schlenker, B., \& Leary, M. (1982). Social anxiety and self-presentation: A conceptualization and model. Psychological Bulletin, 92, 641-669.

Schlenker, B., Weigold, M., \& Hallam, J. (1990). Self-serving attributions in social context: Effects of self-esteem and social pressure. Journal of Personality and Social Psychology, 58, 855-863.

Schlosser, A. (1997). Examining the instrumentality of attitudes: The interactive effect of social context, medium, and product type on product responses. Unpublished doctoral dissertation, Department of Psychology, University of Illinois at Urbana-Champaign.

Schlosser, A., \& Shavitt, S. (1999). Effects of an approaching group discussion on product responses. Journal of Consumer Psychology, 8, 377-406.

Seymour, D. (1987). Focus groups and the development of new products by technologically driven companies: A comment. Journal of Product Innovation Management, 4, 50-54.

Shavitt, S. (1990). The role of attitude objects in attitude functions. Journal of Experimental Social Psychology, 26, 124-148.

Sheffield, J., \& Byrne, D. (1967). Attitude similarity-dissimilarity, authoritarianism, and interpersonal attraction. Journal of Social Psychology, $71,117-123$.

Smith, M., Bruner, J., \& White, R. (1956). Opinions and personality. New York: Wiley

Snell, W., Jr. (1989). Willingness to self-disclose to female and male friends as a function of social anxiety and gender. Personality and Social Psychology Bulletin, 15, 113-125.

Snyder, M. (1974). The self-monitoring of expressive behavior. Journal of Personality and Social Psychology, 30, 526-537.

Snyder, M. (1987). Public appearances private realities: The psychology of self-monitoring. New York: Freeman. 
Snyder, M., \& DeBono, K. (1985). Appeals to image and claims about quality: Understanding the psychology of advertising. Journal of Personality and Social Psychology, 49, 586-597.

Snyder, M., \& Swann, W., Jr. (1976). When actions reflect attitudes: The politics of impression management. Journal of Personality and Social Psychology, 34, 1034-1042.

Stewart, D., \& Shamdasani, P. (1990). Focus groups: Theory and practice. Newbury Park, CA: Sage.

Stewart, D., \& Shamdasani, P. (1998). Focus group research: Exploration and discovery. In L. Bickman \& D. Rog (Eds.), Handbook of applied social research methods (pp. 505-526). Thousand Oaks, CA: Sage.

Sykes, R., Larntz, K., \& Fox, J. (1976). Proximity and similarity effects on frequency of interaction in a class of naval recruits. Sociometry, 39, 263-269.

Templeton, J. (1994). The focus group (Rev. ed.). Chicago: Irwin.

Tice, D., Butler, J., Muraven, M., \& Stillwell, A. (1995). When modesty prevails: Differential favorability of self-presentation to friends and strangers. Journal of Personality and Social Psychology, 69, 1120-1138.
Vaughn, S., Schumm, J., \& Sinagub, J. (1996). Focus group interviews in education and psychology. Thousand Oaks, CA: Sage.

Wells, W. (1974). Group interviewing. In R. Ferber (Ed.), Handbook of marketing research (pp. 2-133-2-146). New York: McGraw-Hill.

Wolfe, R., Lennox, R., \& Cutler, B. (1986). Getting along and getting ahead: Empirical support for a theory of protective and acquisitive self-presentation. Journal of Personality and Social Psychology, 50, 356-361.

Wood, J., Giordano-Beech, M., Taylor, K., Michela, J., \& Gaus, V. (1994). Strategies of social comparison among people with low self-esteem: Self-protection and self-enhancement. Journal of Personality and Social Psychology, 67, 713-731.

Wooten, D. (1995). One-of-a-kind in a full house: Some consequences of ethnic and gender distinctiveness. Journal of Consumer Psychology, 4, 205-224.

Yoell, W. (1974). How useful is focus group interviewing? Not very ... Post-interviews reveal. Marketing Review, 29, 15-19.

Accepted by Frank Kardes. 